\title{
QUÍMICA DO ENSINO MÉDIO TÉCNICO E ENEM: UMA COMPARAÇÃO CURRICULAR
}

\section{ARTIGO ORIGINAL}

GORTZ, Julia Santana ${ }^{1}$, TATY, Salvador Rodrigues², FECURY, Amanda Alves ${ }^{3}$, DENDASCK, Carla Viana ${ }^{4}$, OLIVEIRA, Euzébio de ${ }^{5}$, DIAS, Claudio Alberto Gellis de Mattos $^{6}$

GORTZ, Julia Santana. Et al. Química do ensino médio técnico e Enem: uma comparação curricular. Revista Científica Multidisciplinar Núcleo do Conhecimento. Ano 06, Ed. 03, Vol. 03, pp. 89-99. Março de 2021. ISSN: 2448-0959, Link de acesso: https://www.nucleodoconhecimento.com.br/educacao/comparacaocurricular, DOI: 10.32749/nucleodoconhecimento.com.br/educacao/comparacaocurricular

\section{RESUMO}

O Exame Nacional do Ensino Médio (ENEM) é uma avaliação constituída por uma redação e por questões de múltipla escolha. Esta avalição tem como objetivo mensurar os conhecimentos adquiridos ao longo do Ensino Médio. O objetivo deste artigo é comparar o conteúdo das questões do componente Química do Exame

\footnotetext{
${ }^{1}$ Estudante do Curso Técnico de Química (segundo grau) do Instituto de Ensino Básico, Técnico e Tecnológico do Amapá (IFAP).

${ }^{2}$ Químico, Mestre em Química (UFMA), Professor e pesquisador do Curso de Licenciatura em Química do Instituto de Ensino Básico, Técnico e Tecnológico do Amapá (IFAP), Coordenador do Curso técnico em Química (IFAP).

${ }^{3}$ Biomédica, Doutora em Doenças Topicais (UFPA), Professora e pesquisadora do Curso de Medicina do Campus Macapá, Universidade Federal do Amapá (UNIFAP).

${ }^{4}$ Teóloga, Doutora em Psicanálise, pesquisadora do Centro de Pesquisa e Estudos Avançados- CEPA.

${ }^{5}$ Biólogo, Doutor em Doenças Topicais (UFPA), Professor e pesquisador do Curso de Educação Física da, Universidade Federal do Pará (UFPA).

${ }^{6}$ Biólogo, Doutor em Teoria e Pesquisa do Comportamento (UFPA), Professor e pesquisador do Curso de Licenciatura em Química do Instituto de Ensino Básico, Técnico e Tecnológico do Amapá (IFAP) e do Programa de Pós Graduação em Educação Profissional e Tecnológica (PROFEPT IFAP).
}

RC: 77708

Disponível em: https://www.nucleodoconhecimento.com.br/educacao/comparacao- 
Nacional do Ensino Médio (ENEM) entre os anos de 2014 a 2018 com o conteúdo curricular do curso técnico de química do Instituto Federal do Amapá (IFAP). pesquisa foi realizada utilizando questões de química do Exame Nacional do Ensino Médio (ENEM) retiradas do programa (software) Super professor. O conteúdo ensinado nos três anos do curso técnico em química do Instituto Federal do Amapá (IFAP) atende o requisitado no Exame Nacional do Ensino Médio (ENEM). A carga horária também é suficiente para o desenvolvimento das disciplinas básicas e técnicas. A análise de conteúdo demonstra que, por ser um curso técnico, disponibiliza conhecimento aprofundado, o que aumenta o subsídio para realização do ENEM. Este conteúdo é formado por teoria e também por uma grande experiência pratica (laboratorial). O conhecimento prático auxilia enormemente a fixação do aprendizado e propicia conhecimento para discutir os conteúdos.

Palavras-chave: Ensino, Química, ENEM, EPT, Currículo.

\section{INTRODUÇÃO}

O Exame Nacional do Ensino Médio (ENEM) é uma avaliação constituída por uma redação e por questões de múltipla escolha. As questões são correspondentes às áreas de Ciências Humanas e suas Tecnologias (História, Geografia, Filosofia e Sociologia|); Ciências da natureza e suas tecnologias (Física, Química e Biologia); Linguagens, Códigos e suas tecnologias (Língua Portuguesa, Língua estrangeira, Artes e Educação Física); e matemática e suas tecnologias (Matemática). Esta avalição tem como objetivo mensurar os conhecimentos adquiridos ao longo do Ensino Médio (Moretto e Wittke, 2018).

Um instituto federal é uma instituição com o objetivo de suprir a necessidade de mão de obra técnica qualificada, de forma que os estudantes tenham uma melhor preparação por adquirirem tanto os conhecimentos básicos e como conhecimentos técnicos (Alves et al., 2013; Penha et al., 2020). Atualmente existem 38 institutos federais que estão presentes em todos os estados (Brasil, 2018).

RC: 77708

Disponível em: https://www.nucleodoconhecimento.com.br/educacao/comparacao- 
Em 2007, no dia 25 de outubro, foi criada a Escola Técnica Federal do Amapá (ETFAP). No dia 29 de dezembro de 2008, devido à Lei no 11.892, o ETFAP é transformado em Instituto Federal de Educação, Ciência e Tecnologia do Amapá (IFAP) (Brasil, 2019; Marques et al., 2020).

Seu público alvo é $50 \%$ do nível médio, curso técnico vinculado ao ensino médio (integrado, subsequente e concomitante); $30 \%$ do nível superior, bacharelados e tecnológicos e $20 \%$ para licenciatura. Também possuindo pós-graduação: Lato Sensu e Stricto Sensu (Brasil, 2019; Castro et al., 2020).

O curso de química foi aberto no ano de 2017, tendo 3 anos de duração em regime integral. Ele tem como função, formar técnicos capazes de operar, controlar e monitorar processos industriais e laboratoriais. Manter o controle da qualidade de matérias-primas, insumos e produtos. Realizar amostras, análises químicas, físicoquímicas e microbiológicas. Desenvolver processos e produtos. Os profissionais formados por este curso têm como campo de atuação: indústrias químicas; Laboratórios de controle de qualidade, de certificação de produtos químicos, alimentícios e afins (Brasil, 2019a).

No ensino médio técnico em química ofertado pelo Instituto Federal do Amapá, é previsto na ementa que seja visto no primeiro ano: química geral (a química em nosso cotidiano, a evolução dos modelos atômicos e ligações químicas, funções inorgânicas; problemas ambientais e reações químicas) e matérias técnicas (química experimental, química inorgânica e química orgânica). No segundo ano é visto: química geral (soluções, reações exotérmicas e endotérmicas, velocidade, fatores, equilíbrio e deslocamento e eletroquímica) e matérias técnicas (físico-química, química analítica, análise instrumental e corrosão). Por fim no terceiro ano: química geral (química orgânica, hidrocarbonetos funções oxigenadas, nitrogenadas e mistas e propriedades orgânicas) e matérias técnicas (petróleo e polímeros, processos químicos industriais e tecnologia de biocombustíveis) (Brasil, 2016).

RC: 77708

Disponível em: https://www.nucleodoconhecimento.com.br/educacao/comparacao- 
O conteúdo das questões de química do Enem está dividido em 10 unidades principais, sendo estes: Transformações químicas (onde estão incluídos os assuntos de número atômico, número de massa, isótopos, massa atômica, tabela periódica e reações químicas); Representação das transformações químicas (tópico que inclui balanceamento de equações químicas e cálculos estequiométricos); Materiais, suas propriedades e usos (que inclui propriedades de materiais, estados físicos de materiais, mudanças de estado, misturas e forças intermoleculares); Água (o qual inclui soluções, ácidos, bases, sais e óxidos, nomenclatura e indicadores); Transformações químicas e energia (onde estão inseridos conteúdos como entalpia, equações termoquímicas, lei de Hess, pilha e eletrólise); Dinâmica das transformações químicas (que inclui velocidade de reação e energia de ativação); Transformação química e equilíbrio ( que engloba os assuntos de constante de equilíbrio, equilíbrio ácido-base e $\mathrm{pH}$, solubilidade dos sais e hidrólise); Compostos de carbono (engloba funções orgânicas, hidrocarbonetos e polímeros); Relações da química com as tecnologias, a sociedade e o meio Ambiente ( inclui o assunto de poluição); Energias químicas no cotidiano (inclui os assuntos de petróleo, gás natural e carvão) (Brasil, 2015).

\section{OBJETIVOS}

Comparar o conteúdo das questões do componente Química do Exame Nacional do Ensino Médio (ENEM) entre os anos de 2014 a 2018 com o conteúdo curricular do curso técnico de química do Instituto Federal do Amapá (IFAP).

\section{METODOLOGIA}

A pesquisa foi realizada utilizando questões de química do Exame Nacional do Ensino Médio (ENEM) retiradas do programa (software) Super professor, adquirido da empresa Interbits Informática

(https://www.sprweb.com.br/mod_superpro/index.php). No programa foi selecionada a disciplina química e os anos de 2014 a 2018. Utilizou-se classificação das RC: 77708

Disponível em: https://www.nucleodoconhecimento.com.br/educacao/comparacao- 
questões de acordo com o programa. Posteriormente fez-se uma comparação entre estas e o conteúdo programático do componente química do curso técnico do Instituto Federal do Amapá (IFAP). A pesquisa bibliográfica foi realizada em artigos científicos, em computadores do Instituto no Instituto Federal de Educação, Ciência e Tecnologia do Amapá, Campus Macapá, situado à Rodovia BR 210 KM 3, s/n Bairro Brasil Novo. CEP: 68.909-398, Macapá, Amapá, Brasil. Os dados foram compilados no aplicativo Excel, componente do pacote Office da Microsoft Corporation.

\section{RESULTADOS}

A tabela 1 mostra o conteúdo das questões de química do ENEM entre 2014 e 2018, por quantidade e porcentagem de questões. Essas questões correspondem a $78,82 \%$ do total de questões do período. As questões sobre enzimas, hidratos de carbono, indicadores, mudanças de estado, símbolos, poluição e propriedades físico-químicas não aparecem no período $(0.00 \%)$. Questões sobre estrutura do átomo, cinética química, densidade, propriedades coligativas, soluções, classificação periódica, equacionamento e balanceamento de reações, funções inorgânicas, práticas de laboratório, substância e mistura, cadeias carbônicas, isomeria plana, petróleo e polímeros aparecem $1.18 \%$. Perguntas sobre concentrações das soluções, equilíbrio químico ou iônico, hidrólise de sais, oxido-redução e funções são 2,35\%. Questionamentos sobre ligações químicas e geometria molecular, radioatividade e isomeria espacial correspondem a 3.53\%. Cálculo estequiométrico e separação de misturas correspondem a $4,71 \%$ das questões. Perguntas sobre termoquímica e reações orgânicas são $7,06 \%$. Forças intermoleculares e eletroquímica aparecem $8,24 \%$.

RC: 77708

Disponível em: https://www.nucleodoconhecimento.com.br/educacao/comparacao- 
Tabela 1 Classificação do conteúdo das questões de química do ENEM entre 2014 e 2018, por quantidade e porcentagem de questões.

\begin{tabular}{|c|c|c|}
\hline \multicolumn{3}{|c|}{ Classificaçăo do autor após analise de conteúdo } \\
\hline Conteúdo de Química & Quantidade & Porcentagem \\
\hline Enzimas & 0 & $0.00 \%$ \\
\hline Hidratos de Carbono & 0 & $0.00 \%$ \\
\hline Indicadores & 0 & $0.00 \%$ \\
\hline Mudanças de Estado & 0 & $0.00 \%$ \\
\hline Símbolos & 0 & $0.00 \%$ \\
\hline Poluição & 0 & $0.00 \%$ \\
\hline Propriedades Físico-Químicas & 0 & $0.00 \%$ \\
\hline Estrutura do atomo & 1 & $1.18 \%$ \\
\hline Cinética Química & 1 & $1.18 \%$ \\
\hline Densidade & 1 & $1.18 \%$ \\
\hline Propriedades Coligativas & 1 & $1.18 \%$ \\
\hline Soluções & 1 & $1.18 \%$ \\
\hline Class ificação Periódica & 1 & $1.18 \%$ \\
\hline Equacionamento e Balanceamento de Reações & 1 & $1.18 \%$ \\
\hline Funções Inorgânicas & 1 & $1.18 \%$ \\
\hline Práticas de Laboratório & 1 & $1.18 \%$ \\
\hline Substância e Mistura & 1 & $1.18 \%$ \\
\hline Cadeias Carbônicas & 1 & $1.18 \%$ \\
\hline Isomeria Plana & 1 & $1.18 \%$ \\
\hline Petróleo & 1 & $1.18 \%$ \\
\hline Polímeros & 1 & $1.18 \%$ \\
\hline Concentraçôes das Soluções & 2 & $2.35 \%$ \\
\hline Equilíbrio Químico ou lônico & 2 & $2.35 \%$ \\
\hline Hidrólise de Sa is & 2 & $2.35 \%$ \\
\hline Óxido-redução & 2 & $2.35 \%$ \\
\hline Funções & 2 & $2.35 \%$ \\
\hline Ligações Químicas e Geometria Molecular & 3 & $3.53 \%$ \\
\hline Radioatividade & 3 & $3.53 \%$ \\
\hline Isomeria Espacial & 3 & $3.53 \%$ \\
\hline Cálculo Estequiométrico & 4 & $4.71 \%$ \\
\hline Separação de Misturas & 4 & $4.71 \%$ \\
\hline Termoquímica & 6 & $7.06 \%$ \\
\hline Reações Orgânicas & 6 & $7.06 \%$ \\
\hline Forças intermoleculares & 7 & $8.24 \%$ \\
\hline Eletroquímica & 7 & $8.24 \%$ \\
\hline
\end{tabular}

RC: 77708

Disponível em: https://www.nucleodoconhecimento.com.br/educacao/comparacaocurricular 
A tabela 2 mostra o conteúdo sobreposto das questões de química do ENEM entre 2014 e 2018, por quantidade e porcentagem de questões. As questões sobrepostas representam $21.18 \%$ do total da prova, no período. As questões Forças intermoleculares + Propriedades Físico-Químicas, Forças intermoleculares + Propriedades coligativas, Forças intermoleculares + Separação de misturas, Ligações químicas e geometria molecular + classificação periódica, Hidrólise de sais + Equacionamento e balanceamento de reações + Funções inorgânicas, Equilíbrio químico ou iônico + Polímeros, Hidratos de carbono + Óxido-redução, Hidrólise de sais + Indicadores, Símbolos + Substância e mistura, Equacionamento e balanceamento de reações + Poluição e Poluição + Cadeias carbônicas aparecem $1,18 \%$. Os problemas de assunto de Enzimas + Reações orgânicas, Concentrações das soluções + Soluções representam 2,35\%.

Tabela 2 Classificação do conteúdo sobreposto das questões de química do ENEM entre 2014 e 2018, por quantidade e porcentagem de questões. As questões sobrepostas representam $21.18 \%$

\begin{tabular}{l|c|c|}
\hline \multicolumn{2}{c}{ Classificação do autor após analise de conteúdo sobre posto } \\
\hline \multicolumn{1}{c|}{ Conteúdo de Química } & Quantidade & Porcentagem \\
\hline Forças intermoleculares + Propriedades Fisico-Quimicas & 1 & $1.18 \%$ \\
\hline Forças intermoleculares + propriedades coligativas & 1 & $1.18 \%$ \\
\hline Forças Intermoleculares + Separação de Misturas & 1 & $1.18 \%$ \\
\hline Forças Intermolecula res + Mudanças de Estado & 1 & $1.18 \%$ \\
\hline Ligações Químicas e Geometria Molecular + Classificação Periódica & 1 & $1.18 \%$ \\
\hline $\begin{array}{l}\text { Hidrólise de Sais + Equacionamento e Balanceamento de Reações + } \\
\text { Funções Inorgânicas }\end{array}$ & 1 & $1.18 \%$ \\
\hline Equilíbrio Químico ou lônico + Polímeros & 1 & $1.18 \%$ \\
\hline Hidratos de Carbono + Óxido-redução & 1 & $1.18 \%$ \\
\hline Hidrólise de Sais + Indicadores & 1 & $1.18 \%$ \\
\hline Simbolos + Substância e Mistura & 1 & $1.18 \%$ \\
\hline Equacionamento e Balanceamento de Reações + Poluição & 1 & $1.18 \%$ \\
\hline Poluição + Cadeias Carbônicas & 1 & $1.18 \%$ \\
\hline Enzimas + Reações Orgânicas & 2 & $2.35 \%$ \\
\hline Concentrações das Soluções + Soluções & 2 & $2.35 \%$ \\
\hline Cadeias Carbônicas + Reações Orgânicas & 2 & $2.35 \%$ \\
\hline
\end{tabular}

RC: 77708

Disponível em: https://www.nucleodoconhecimento.com.br/educacao/comparacao- 
Os assuntos da ementa de química do curso técnico em química do IFAP, por ano e unidade (referente a cada bimestre), estão demonstrados na tabela 3. No curso de química as matérias são divididas entre as normais do ensino médio e as matérias técnicas, as quais são especificas do curso. Nas disciplinas da tabela curricular padrão, o componente utilizado, nos três anos, é a química geral. Sua carga horaria total é de 240 horas, 80 horas em cada ano. No primeiro ano a sua primeira unidade é dada em 15 horas, a segunda unidade em 20 horas, a terceira em 25 horas e a quarta em 20 horas. No segundo ano o primeiro conteúdo é dado em 15 horas, o segundo conteúdo em 15 horas, o terceiro em 25 horas e o quarto em 25 horas. No terceiro ano a primeira unidade tem uma carga horaria de 15 horas, a segunda unidade possui uma carga horaria de 20 horas, a terceira de 30 horas e a quarta de 15 horas.

As outras disciplinas (curriculares técnicas) citadas na tabela 3 são matérias técnicas especificas do curso, estas são semestrais e possuem uma carga horaria total de 80 horas por semestre cada. No primeiro ano são citadas as matérias: química experimental, que possui uma carga horaria de 10 horas, 20 horas, 25 horas e 25 horas para as unidades um, dois, três e quatro respectivamente; química inorgânica, com uma carga horaria de 15 horas para a primeira unidade, 15 horas para a segunda unidade, 25 horas para a terceira unidade e 25 horas para a quarta unidade; química orgânica, cuja primeira unidade é dada em 25 horas, a segunda unidade em 15 horas, a terceira em 20 horas e a quarta em 20 horas. No segundo ano as matérias técnicas são as seguintes: Físico-química, com sua primeira unidade dada em 25 horas, sua segunda unidade dada em 20 horas, a terceira em 20 horas e a quarta em 15 horas; química analítica, com 18 horas para sua primeira unidade, 20 horas para a segunda unidade, 23 horas para a terceira unidade e 19 horas para a quarta unidade; analise instrumental, com suas quatro unidades são dadas em, respectivamente, 10 horas, 20 horas, 25 horas e 25 horas; corrosão, onde sua primeira unidade é dada em 10 horas, sua segunda unidade é dada em 25 horas, sua terceira unidade é dada em 20 horas e sua quarta em 25 horas. No

RC: 77708

Disponível em: https://www.nucleodoconhecimento.com.br/educacao/comparacao- 
terceiro ano as disciplinas especificas citadas na tabela são: petróleo e polímeros, com suas unidades dadas em 18 horas, 22 horas, 22 horas e 18 horas respectivamente; processos químicos industriais, com sua primeira unidade dada em 25 horas, a segunda unidade é dada em 20 horas, a terceira em 20 horas e a quarta em 15 horas; tecnologia de biocombustíveis, com sua carga horaria de 25 horas para a primeira unidade, 25 horas para a segunda unidade, 10 horas para a terceira e 20 para a quarta.

RC: 77708

Disponível em: https://www.nucleodoconhecimento.com.br/educacao/comparacao- 
Tabela 3. Assuntos da ementa de química do curso técnico em química do IFAP, por ano e unidade.

DISAPLINA CURRICULAR PADRĀO

\begin{tabular}{|c|c|c|c|c|c|c|}
\hline \multirow[b]{2}{*}{ Unidade } & \multicolumn{6}{|c|}{ Ano } \\
\hline & $1^{\circ}$ ANO & $\begin{array}{c}n^{\circ} \text { de } \\
\text { horas aula }\end{array}$ & $2^{\circ}$ ANO & de horas at & $3^{\circ} \mathrm{ANO}$ & $\begin{array}{c}\mathbf{n}^{\circ} \text { de } \\
\text { horas aula }\end{array}$ \\
\hline I & $\begin{array}{c}\text { A. Quimica emnosso } \\
\text { cotidiano }\end{array}$ & 15 horas & Sohções & 15 horas & Quimica Orgânica & 15 horas \\
\hline II & $\begin{array}{l}\text { A evobção dos } \\
\text { modelos atômicos e } \\
\text { ligacões Qvímic as. }\end{array}$ & 20 horas & $\begin{array}{l}\text { Reações exotérmicas } \\
\text { e endotérmicas }\end{array}$ & 15 horas & Hidrocarb onetos & 20 horas \\
\hline III & $\begin{array}{c}\text { Funções Inorgânicas } \\
\text { e problemas } \\
\text { anbientais }\end{array}$ & 25 horas & $\begin{array}{c}\text { Velocidiade, fatores, } \\
\text { equilibrio e } \\
\text { deslocamento }\end{array}$ & 25 horas & $\begin{array}{l}\text { Funções Oxigenadas, } \\
\text { nitrogenadas e mis tas }\end{array}$ & 30 horas \\
\hline IV & Reações Quimicas & 20 horas & Eletro-Quimica & 25 horas & $\begin{array}{c}\text { Propriedades } \\
\text { Orgânicas }\end{array}$ & 15 horas \\
\hline & & 80 horas & & 80 horas & & 80 horas \\
\hline
\end{tabular}

DISCIPLINA CURRICULAR TÉCNICA - 1 ANO

\begin{tabular}{|c|c|c|c|c|c|c|}
\hline \multirow[b]{2}{*}{ Unidade } & \multicolumn{6}{|c|}{ Ano } \\
\hline & $\begin{array}{c}\text { Quimica } \\
\text { Experimental }\end{array}$ & $\begin{array}{c}\mathbf{n}^{\circ} \text { de } \\
\text { horas aula }\end{array}$ & $\begin{array}{l}\text { Quimica } \\
\text { Inorgânica }\end{array}$ & $\begin{array}{c}\mathbf{n}^{\circ} \text { de } \\
\text { horas aula }\end{array}$ & $\begin{array}{l}\text { Quimica } \\
\text { Orgânica }\end{array}$ & $\begin{array}{c}\mathbf{n}^{\circ} \mathrm{de} \\
\text { horas aula }\end{array}$ \\
\hline I & $\begin{array}{c}\text { Introdução a os } \\
\text { trabalhos em } \\
\text { laboratónio. }\end{array}$ & 10 horas & $\begin{array}{l}\text { Quimica dos não } \\
\text { metais }\end{array}$ & 15 horas & $\begin{array}{c}\text { Introdução a } \\
\text { mecanismo de reação }\end{array}$ & 25 horas \\
\hline II & $\begin{array}{c}\text { Obtenção e us o de } \\
\text { calor }\end{array}$ & 20 horas & Quimica dos metais & 15 horas & Ácidos e Bases & 15 horas \\
\hline III & $\begin{array}{c}\text { Process os de } \\
\text { separação de mis turas }\end{array}$ & 25 horas & $\begin{array}{l}\text { Compostos de } \\
\text { coordenação }\end{array}$ & 25 horas & $\begin{array}{c}\text { Reações de adição- } \\
\text { eliminação } \\
\text { nucleofilica em } \\
\text { carbono acilico }\end{array}$ & 20 horas \\
\hline IV & $\begin{array}{c}\text { Estudo das reações } \\
\text { Quimicas }\end{array}$ & 25 horas & $\begin{array}{l}\text { Estrutura de sólidos } \\
\text { cristalinos e amorfos }\end{array}$ & 25 horas & $\begin{array}{l}\text { Reações de } \\
\text { substituição } \\
\text { eletrofilica em } \\
\text { aromáticos }\end{array}$ & 20 horas \\
\hline & & 80 horas & & 80 horas & & 80 horas \\
\hline
\end{tabular}

\begin{tabular}{|c|c|c|c|c|c|c|c|c|}
\hline \multirow[b]{2}{*}{ Unidade } & \multicolumn{8}{|c|}{ Ano } \\
\hline & Fisico Quimira & $\begin{array}{c}\mathbf{n}^{\circ} \text { de } \\
\text { horas aula }\end{array}$ & Quimica Analítica & $\begin{array}{c}\mathbf{n}^{\circ} \text { de } \\
\text { horas aula }\end{array}$ & $\begin{array}{c}\text { Análise } \\
\text { Instrumental }\end{array}$ & $\begin{array}{c}\mathrm{n}^{\circ} \text { de } \\
\text { horas aula }\end{array}$ & Corrosão & $\begin{array}{c}\mathrm{n}^{\circ} \text { de horas } \\
\text { aula }\end{array}$ \\
\hline I & $\begin{array}{c}\text { Solvçōes , Dispersões } \\
\text { e Propriadades } \\
\text { Coligativas }\end{array}$ & 25 horas & $\begin{array}{c}\text { Introduçäo, Tecnic as } \\
\text { e Métodos }\end{array}$ & 18 horas & $\begin{array}{c}\text { Introdução a aná lise } \\
\text { instrumental }\end{array}$ & 10 horas & Introd vção a corrosão & 10 horas \\
\hline II & Equilibrio Quimico & 20 horas & $\begin{array}{l}\text { Titulometria de } \\
\text { neutralizaçảo e } \\
\text { precipitaçäo }\end{array}$ & 20 horas & $\begin{array}{c}\text { Métodos } \\
\text { ele troan aliticos }\end{array}$ & 20 horas & $\begin{array}{c}\text { Princ ipios básicos da } \\
\text { corrosảo } \\
\text { eletroQuímica }\end{array}$ & 25 horas \\
\hline III & Cinética Quimica & 20 horas & $\begin{array}{c}\text { Titulometria de } \\
\text { complexaça âo e oxi- } \\
\text { redução }\end{array}$ & 23 horas & $\begin{array}{c}\text { Métodos } \\
\text { espectros cópicos }\end{array}$ & 25 horas & $\begin{array}{c}\begin{array}{c}\text { Princ ípios básicos da } \\
\text { corrosảo Quimica }\end{array} \\
\end{array}$ & 20 horas \\
\hline IV & $\begin{array}{c}\text { Es tudo dos } \\
\text { Processos de Troca } \\
\text { de Calor nos } \\
\text { Equilibrios }\end{array}$ & 15 horas & Laboratónio, Cakcu los & 19 horas & $\begin{array}{c}\text { Métodos } \\
\text { cromatográficos }\end{array}$ & 25 horas & $\begin{array}{c}\text { Res istênc ia à } \\
\text { corros ảo e proteçảo } \\
\text { an ticorro siva }\end{array}$ & 25 horas \\
\hline & & 80 horas & & 80 horas & & 80 horas & & 80 horas \\
\hline
\end{tabular}

RC: 77708

Disponível em: https://www.nucleodoconhecimento.com.br/educacao/comparacao- 
DISCIPLINA CURRICULAR TÉCNICA - 3 ANO

\begin{tabular}{|c|c|c|c|c|c|c|}
\hline \multirow[b]{2}{*}{ Unidade } & \multicolumn{6}{|c|}{ Ano } \\
\hline & $\begin{array}{l}\text { Petróleo e } \\
\text { Polímeros }\end{array}$ & $\begin{array}{c}n^{\circ} \text { de } \\
\text { horas aula }\end{array}$ & $\begin{array}{l}\text { Processos } \\
\text { Qúnicos } \\
\text { Industriais }\end{array}$ & $\begin{array}{c}n^{\circ} \text { de } \\
\text { horas aula }\end{array}$ & $\begin{array}{c}\text { Tecnologia de } \\
\text { Biocombustiveis }\end{array}$ & $\begin{array}{c}\mathbf{n}^{\circ} \text { de } \\
\text { horas aula }\end{array}$ \\
\hline I & $\begin{array}{c}\text { Process os } \\
\text { tecnológicos de } \\
\text { petróleo e polimeros e } \\
\text { Leg is lação pertinente }\end{array}$ & 18 horas & $\begin{array}{l}\text { Tratamento de água, } \\
\text { Importancia do } \\
\text { Tratamento de } \\
\text { Efluentes, Parâmetros } \\
\text { de polvição hidrica e } \\
\text { Classificação de } \\
\text { residuos }\end{array}$ & 25 horas & $\begin{array}{l}\text { Etapas Quimicas da } \\
\text { Sintese de Etanol e do } \\
\text { Biodiesel; Anális e } \\
\text { Quimica de Qualidade } \\
\text { de Produção de Mini - } \\
\text { Usinas Pequeno, } \\
\text { Médio e Grande Porte }\end{array}$ & 25 horas \\
\hline II & $\begin{array}{l}\text { Controle de qualidade } \\
\text { e Fundamentos do } \\
\text { petróleo e dos } \\
\text { polimeros }\end{array}$ & 22 horas & $\begin{array}{c}\text { Tratamento e } \\
\text { disposição final de } \\
\text { efluentes de } \\
\text { residvo, Formas de } \\
\text { tratamentos, Tipos de } \\
\text { tratamento e descarte } \\
\text { e Tpos de } \\
\text { equipamentos } \\
\end{array}$ & 20 horas & $\begin{array}{c}\text { Produção e Análise } \\
\text { Quimica de } \\
\text { Biocombus tiveis em } \\
\text { Escala Laboratoriale } \\
\text { Industrial }\end{array}$ & 25 horas \\
\hline ШI & $\begin{array}{l}\text { Indústria do petróleo } \\
\text { e petroQvimica e } \\
\text { Logis tica do petróleo }\end{array}$ & 22 horas & $\begin{array}{c}\text { Programas de } \\
\text { reutilização, } \\
\text { Resolvção de } \\
\text { problemas de } \\
\text { produção e } \\
\text { qualidade de } \\
\text { a limentos, Otimiza ção } \\
\text { na produção de } \\
\text { oleaginos as e açúcar }\end{array}$ & 20 horas & $\begin{array}{l}\text { Produção de Bio- } \\
\text { Etanol e Biodiesel }\end{array}$ & 10 horas \\
\hline IV & $\begin{array}{l}\text { Produção de } \\
\text { polimeros e } \\
\text { Reciclagem de } \\
\text { polimeros }\end{array}$ & 18 horas & $\begin{array}{c}\text { Otimização na } \\
\text { produção de álcool, } \\
\text { Oleaginos as da região } \\
\text { e Reações Quimicas } \\
\text { dos mais importantes } \\
\text { processos industriais }\end{array}$ & 15 horas & $\begin{array}{l}\text { Aspectos } \\
\text { operacionais de } \\
\text { usinas de etanol } \\
\text { biodiesele, } \\
\text { combus tiveis de } \\
\text { Terceira geração }\end{array}$ & 20 horas \\
\hline & & 80 horas & & 80 horas & & 80 horas \\
\hline
\end{tabular}

A soma das questões de química do ENEM entre 2014 e 2018, por grau de dificuldade, por ano aparece na figura 1. O número de questões com média dificuldade aumentou de sete (7) em 2014 para doze (12) em 2015. Nos dois anos subsequentes houve uma redução, sendo sete (7) questões em 2016 e cinco (5) em 2017. Em 2018 ocorreu um pequeno aumento, totalizando seis (6) questões. Nas questões de complexidade considerada elevada houve uma redução de dez (10) questões em 2014 para cinco (5) em 2015. A partir daí houve um aumento nos dois

RC: 77708

Disponível em: https://www.nucleodoconhecimento.com.br/educacao/comparacao- 
anos seguintes, sendo dez (10) em 2016 e doze (12) em 2017. Em 2018 houve uma pequena queda no número, onze (11) questões).

Figura 1 Mostra a soma das questões de química do ENEM entre 2014 e 2018, por grau de dificuldade, por ano

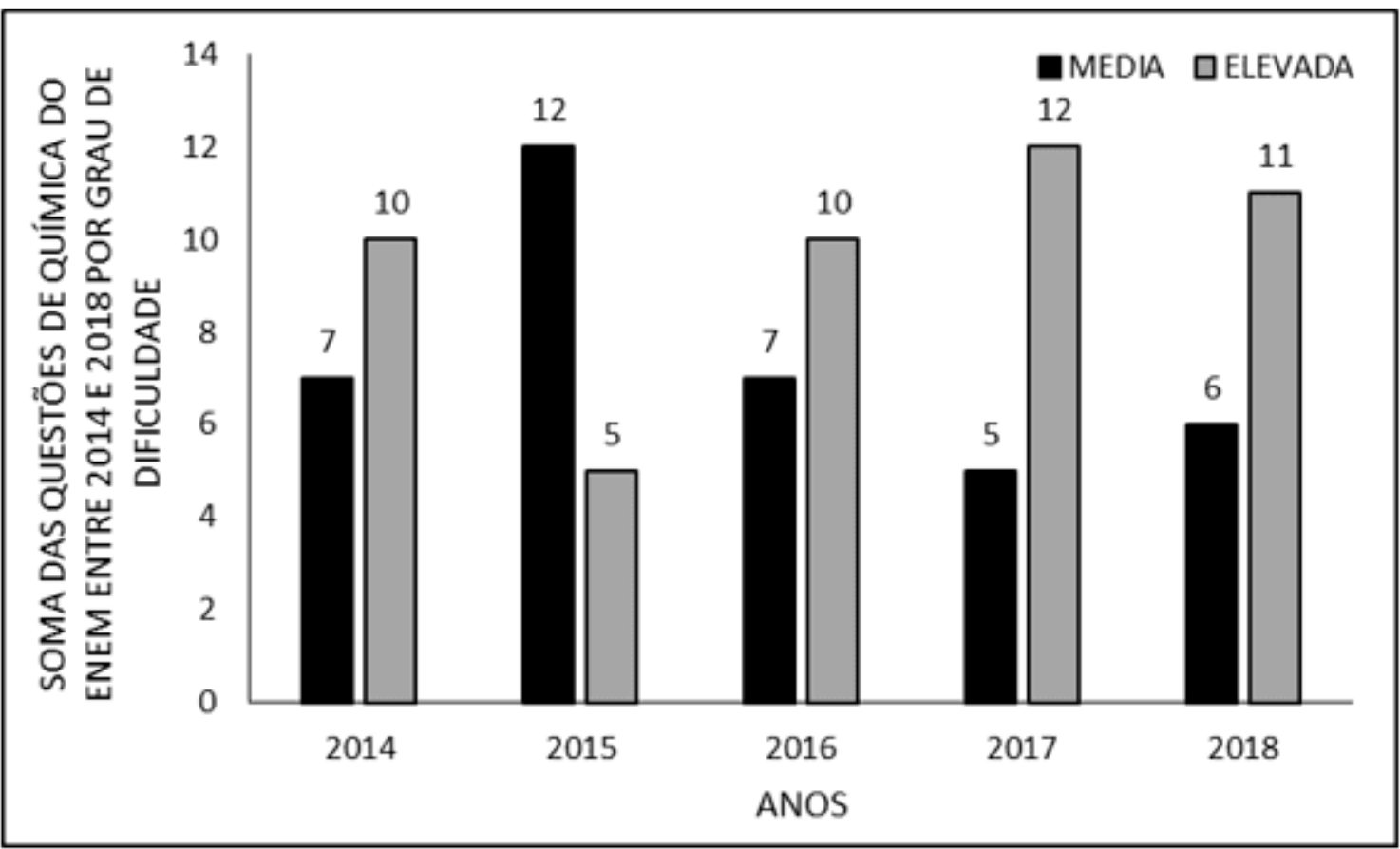

\section{DISCUSSÃO}

A diferença presente nas provas do ENEM avaliadas, quanto a porcentagem de cada conteúdo (Tabela1) provavelmente ocorrem devido a alguns deles serem mais presentes no cotidiano dos estudantes (como reações orgânicas e as ligações entre elas) do que outros (indicadores, mudanças de estado, simbologia). O ENEM preza por contextualizar as suas questões (Hipólito e Silveira, 2011; Silveira et al., 2014).

Os conteúdos do ENEM são sobrepostos porque buscam uma integração entre os tópicos internos da matriz curricular de química e entre esses tópicos e as outras disciplinas (interdisciplinaridade e transversalidade) (Tabela 2). Essa mescla de

RC: 77708

Disponível em: https://www.nucleodoconhecimento.com.br/educacao/comparacao- 
conteúdos ajuda a aproximação destes com o cotidiano dos estudantes. Auxilia, ainda, na mudança curricular para algo menos engessado e mais transversal (Hipólito e Silveira, 2011).

Essa tabela ainda demonstra que a maior parte das questões intradisplinares são a respeito de enzimas, reações orgânicas, soluções e concentração das soluções. Possivelmente isso se deve ao fato de, fisiologicamente, a maioria dos seres vivos funcionarem devido a química da sua estrutura orgânica. Então, mais uma vez, questões assim são mais próximas ao cotidiano dos estudantes (Leite e Velani, 2019).

Os conteúdos podem apresentar diferenças de carga horária (Tabela 3) devido a diferenças de complexidade e também a capacidade de contextualização do conteúdo. Contextualizar o conteúdo é importante para a compreensão e entendimento destes. Como cada docente tem a sua maneira única de ministrá-los, pode haver diferença no tempo curricular programado no planejamento com o tempo real para leciona-los (Pontes et al., 2008).

A área de ciências da natureza é a que possui o maior peso para a área de saúde e biológicas na maioria das universidades públicas do Brasil, como exemplo a USP, uma das universidades de maior prestigio do país. Os cursos na área de saúde são bastantes cobiçados, especialmente por suas remunerações. As questões de química provavelmente buscam manter uma dificuldade (Figura1) mais elevada para que os candidatos com mais conhecimento nessa área de grande importância para o curso entrem com maior conhecimento nestes (Casoni, 2021; Ufpe, 2021).

\section{CONCLUSÃO}

O conteúdo ensinado nos três anos do curso técnico em química do Instituto Federal do Amapá (IFAP) atende o requisitado no Exame Nacional do Ensino Médio (ENEM).

RC: 77708

Disponível em: https://www.nucleodoconhecimento.com.br/educacao/comparacao- 
A carga horária do curso médio técnico em química do IFAP também é suficiente para o desenvolvimento das disciplinas básicas e técnicas, e também propicia uma boa base para o ENEM

A análise de conteúdo do curso tem química do IFAP demonstra que, por ser um curso técnico, disponibiliza conhecimento aprofundado, o que aumenta o subsídio para realização do ENEM. Este conteúdo é formado por teoria e também por uma grande experiência pratica (laboratorial). O conhecimento prático auxilia enormemente a fixação do aprendizado e propicia conhecimento para discutir os conteúdos.

Portanto o conteúdo curricular deste curso técnico atende os requisitos básicos do Exame Nacional.

\section{REFERÊNCIAS}

ALVES, N. B.; PALMA, L. C.; SILVA, T. N. Educação para a sustentabilidade: a construção de caminhos no Instituto Federal de Educação, Ciência e Tecnologia do Rio Grande do Sul (IFRS). Ram, Rev. Adm. Mackenzie, v. 14, n. 3, p. 83-118, 2013.

BRASIL. Matriz de Referência Enem. Brasilia DF, 2015. Disponível em: < http://download.inep.gov.br/download/enem/matriz_referencia.pdf >. Acesso em: 25 mar 2020.

Curso Técnico de Nível Médio em Química na Forma Integrada Regime Integral: Plano de Curso. Macapá AP, 2016. Disponível em: < https://portal.ifap.edu.br/index.php/publicacoes/item/1100-resolucao-n-20-2018consup $>$.

RC: 77708

Disponível em: https://www.nucleodoconhecimento.com.br/educacao/comparacao- 
. Expansão da Rede Federal. Rede Federal de Educação Profissional, Científica e Tecnológica. 2018. Disponível em: < http://redefederal.mec.gov.br/expansao-da-rede-federal >. Acesso em: 20 abr 2020.

Histórico. Macapá AP, 2019. Disponível em: < http://portal.ifap.edu.br/index.php/quem-somos/historico >. Acesso em: 24 abr. 2020. . Curso Técnico em Química - Integrado - Campus Macapá. Macapá AP, 2019a. Disponível em:

http://www.ifap.edu.br/index.php/component/content/article?id=398 >. Acesso em: 24 abr. 2020.

CASONI, L. A. SiSU Simulator. 2021. Disponível em: < https://sisusimulator.com.br/usp/faculdade-de-medicina-da-universidade-de-saopaulo---fm/medicina-bacharelado >. Acesso em: 24 fev 2021

CASTRO, G. N. V. et al. Análise de Eficiência Acadêmica dos cursos subsequentes, nas modalidades à distância e presencial, ofertados pelo Instituto Federal do Amapá (2018). Research, Society and Development, v. 9, n. 8, p. e208985262, 2020. https://rsdjournal.org/index.php/rsd/article/view/5262

HIPÓLITO, A. F.; SILVEIRA, H. E. D. As questões de Química do Exame Nacional do Ensino Médio (ENEM) em um enfoque transversal e interdisciplinar. 2011. Disponível em: < http://abrapecnet.org.br/atas_enpec/viiienpec/resumos/R0237-1.pdf >. Acesso em: 11 fev 2021.

LEITE, K. D. C.; VELANI, V. Divertindo-se com a química: o ensino e a aprendizagem por meio do lúdico. Braz. J. of Develop., v. 5, n. 11, p. 25115-25133, 2019

MARQUES, J. D. C. et al. Nível Médio Técnico e Cursos de Graduação: comparativo de vagas e ingressantes no Instituto Federal do Amapá, Brasil (2017-

RC: 77708

Disponível em: https://www.nucleodoconhecimento.com.br/educacao/comparacao- 
2018). Research, Society and Development, v. 9, n. 8, p. e228985375, 2020. https://rsdjournal.org/index.php/rsd/article/view/5375

MORETTO, M.; WITTKE, C. I. Capacidades de linguagem desenvolvidas em estudantes do ensino médio a partir de uma dinâmica de produção de textos focada no ENEM. Diálogo das Letras, v. 7, n. 2, p. 155 - 172, 2018.

PENHA, A. C. F. M. et al. Matrículas da Educação Especial na Educação Profissional Técnica de Nível Médio no Estado do Amapá (2015-2018). Research, Society and Development, v. 9, n. 7, p. e881974867, 2020. https://rsdjournal.org/index.php/rsd/article/view/4867

PONTES, A. N. et al. O Ensino de Química no Nível Médio: Um Olhar a Respeito da Motivação. XIV Encontro Nacional de Ensino de Química (XIV ENEQ) Curitiba PR: Universidade Federal do Paraná 2008.

SILVEIRA, F. L.; STILCK, J.; BARBOSA, M. Comunicações: Manifesto sobre a qualidade das questões de Física na Prova de Ciências da natureza no Exame Nacional de Ensino Médio. Caderno Brasileiro de Ensino de Física, v. 31, n. 2, p. 473-479, 2014.

UFPE. Relação dos Cursos com novos Pesos e Notas Mínimas do ENEM 2019 que serão aplicados no Processo Seletivo UFPE| SiSU 2020. 2021. Disponível em: < https://www.ufpe.br/documents/38970/2199517/Pesos+e+notas+m\%C3\%ADnimas+ ENEM_UFPE+2020_+Mudan\%C3\%A7as+nos+cursos_03.06.19.pdf/85759192-f4cc4817-8541-026a5e06f7c4 >. Acesso em: 24 fev 2021.

Enviado: Março, 2021

Aprovado: Março, 2021

RC: 77708

Disponível em: https://www.nucleodoconhecimento.com.br/educacao/comparacao- 